Available online at GSC Online Press Directory

GSC Biological and Pharmaceutical Sciences

e-ISSN: 2581-3250, CODEN (USA): GBPSC2

Journal homepage: https://www.gsconlinepress.com/journals/gscbps

(RESEARCH ARTICLE)

\title{
Determination of polyphenolic components by high performance liquid chromatography (HPLC) and evaluation of the antioxidant activity of leaves and fruits of Crataegus mongyna Jacq
}

\author{
Nihed Ziouche ${ }^{1}$, Leila Derradji ${ }^{1, *}$ and Youcef Hadef ${ }^{2}$ \\ ${ }^{1}$ Laboratory of Pharmacognosy, Department of Pharmacy, Faculty of Medicine, Badji Mokhtar-Annaba University, \\ Algeria. \\ ${ }^{2}$ Laboratory of Development and Control of Pharmaceutical Preparations, Department of Pharmacy, Faculty of \\ Medicine, Badji Mokhtar-Annaba University, Algeria.
}

Publication history: Received on 16 October 2020; revised on 27 October 2020; accepted on 28 October 2020

Article DOI: https://doi.org/10.30574/gscbps.2020.13.1.0344

\begin{abstract}
Crataegus mongyna Jacq is an endemic species of eastern Algeria, used in traditional medicine for its many therapeutic virtues. Its leaves and fruits are rich in polyphenols. In the present study we wanted to research its polyphenolic components in which it is rich. The method we used is high performance liquid chromatography (HPLC) and evaluation of the antioxidant activity in the methanolic extracts of its leaves and fruits. For this evaluation we followed the free radical reduction method DPPH (2, 2-diphenyl-1-picryl hydrazyl) by an antioxidant. The results show, the presence of polyphenolic components such as rutin, quercetin and isoquercetin and significant antioxidant activity. Crataegus monogyna Jacq is could be placed as an alternative treatment for certain pathologies because it is of value for public health.
\end{abstract}

Keywords: Crataegus mongyna Jacq; Leaves; Fruits; Methanolic extracts; Polyphenolic components; Antioxidant activity

\section{Introduction}

Crataegus monogyna Jacq is used in traditional medicine for its therapeutic properties. It has been used in traditional medicine for the treatment of cardiovascular disorders [1]. It is a species with antispasmodic and tranquilizing properties, allowing to regulate the tension and to suppress the tachycardia [2]. The activity of standardized extracts has been demonstrated in numerous in vitro or in vivo experiments [3]. The fruits and leaves of Crataegus monogyna Jacq are rich in polyphenolic components, mainly flavonoids [4]. The present study aims to determine these polyphenol components by high performance liquid chromatography (HPLC) and to evaluate the antioxidant activity of the leaves and fruits of this plant. The method that we have recommended is that of the reduction of the free radical DPPH (2, 2diphenyl-1-picryl hydrazyl) by an antioxidant (anti-free radical). The results show the presence of polyphenolic components such as rutin, quercetin and isoquercetin and significant antioxidant activity. Crataegus monogyna Jacq whose pharmacological properties have given it a good place in traditional medicine, could be placed as an alternative treatment for certain pathologies because it is of value for public health.

\footnotetext{
* Corresponding author: Leila Derradji

Laboratory of Pharmacognosy, Department of Pharmacy, Faculty of Medicine, Badji Mokhtar-Annaba University, Algeria. 


\section{Material and methods}

\subsection{Plant material}

The harvest of plant material is carried out in the North-East of Algeria. The plant parts used in this study are the leaves and fruits of Crataegus monogyna Jacq. The leaves were dried out of direct sunlight, at room temperature in a dry and ventilated place and the fruits were dried in an oven at $50{ }^{\circ} \mathrm{C}$ for 20 hours. The dried plant parts are crushed and sieved. The water content is checked (less than 10\%). The recovered powder is stored in a glass container at room temperature and protected from light.

\subsection{Preparation of methanolic extract}

We deposited 2.5 grams (gr) of each part studied (leaves and fruits) in 20 milliliters (ml) of methanol in an Erlenmeyer flask for 24 hours (h) at room temperature. The extracts are then filtered and then evaporated to dryness under reduced pressure using a rotary evaporator. The dry residues are taken up in $10 \mathrm{ml}$ of methanol and stored in amber bottles at $+4^{\circ} \mathrm{C}$. We calculated the residue after each operation to determine the initial concentration of each extract:

- The concentration of methanolic extract of leaf: $\mathrm{ME}_{\text {lea }}=26.4$ milligrams $(\mathrm{mg}) / \mathrm{ml}$.

- The concentration of methanolic extract of fruit: $\mathrm{ME}_{\mathrm{frt}}=94.2 \mathrm{mg} / \mathrm{ml}$.

\subsection{HPLC protocol}

Before starting the chromatographic analysis, the mobile phases, controls and extracts are placed in an ultrasonic tank for degassing. The extracts analyzed are at concentrations of $0.5 \mathrm{mg} / \mathrm{ml}$ for an injected volume of $10 \mathrm{microliter}(\mu \mathrm{l})$ at $40^{\circ} \mathrm{C}$. On the other hand, the solutions of the controls were prepared in methanol at a concentration of $1 \mathrm{mg} / \mathrm{ml}$. After each injection the analytical system was rinsed for 30 minutes with the mobile phase to ensure that any products that might have remained on the column were dislodged. A baseline free of peaks was the prerequisite for any injection. For all the analyzes, the solvents used are of HPLC quality, the flow rate is set at $1 \mathrm{ml} / \mathrm{min}$. The detection was carried out by a UV-Visible detector and the measurement wavelength set at 350 nanometers (nm). The identification of the products on the chromatograms was made by comparing the retention times with those of the standards.

\subsection{DPPH protocol}

\subsubsection{Preparation of the DPPH solution}

We prepared the DPPH solution by dissolving $2 \mathrm{mg}$ of DPPH in $50 \mathrm{ml}$ of methanol. The preparation must be carried out at least two hours in advance for good solubilization. DPPH is characterized by a dark purple color when placed in a methanolic solution.

\subsubsection{Preparation of the dilution of $D P P H$}

We prepared the dilutions of our methanolic extracts of leaves and fruits at different concentrations from the methanolic extract stock solutions of leaves (Meslea) and methanolic extract stock solution of fruits (Mesfrt):

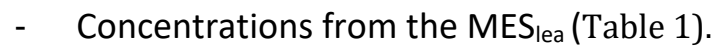

Table 1 Dilutions of methanolic leaf extract

\begin{tabular}{|l|l|l|}
\hline Solution & Concentration in $\mathbf{~ m g} / \mathbf{~ m l}$ & Preparation of the dilution \\
\hline Meslea & $26.4 \mathrm{mg} / \mathrm{ml}$ & \\
\hline DS 1 & 0.264 & $10 \mu \mathrm{l} \mathrm{Meslea}+990 \mu \mathrm{l}$ methanol \\
\hline DS 2 & 0.132 & $1 \mathrm{ml} \mathrm{Dls} 1+1 \mathrm{ml}$ methanol \\
\hline DS 3 & 0.066 & $1 \mathrm{ml}$ Dls $2+1 \mathrm{ml}$ methanol \\
\hline DS 4 & 0.033 & $1 \mathrm{ml}$ Dls $3+1 \mathrm{ml}$ methanol \\
\hline DS 5 & 0.016 & $1 \mathrm{ml}$ Dls $4+1 \mathrm{ml}$ methanol \\
\hline
\end{tabular}

Concentrations from the Mesfrt (Table 2). 
Table 2 Dilutions of methanolic fruit extract

\begin{tabular}{|c|l|l|}
\hline Solution & Concentration in mg / ml & Preparation of the dilution \\
\hline Mes $_{\mathrm{frt}}$ & $94.2 \mathrm{mg} / \mathrm{ml}$ & \\
\hline DS 1 & 0.942 & $10 \mu \mathrm{Mes}_{\mathrm{frt}}+990 \mu \mathrm{l}$ methanol \\
\hline DS 2 & 0.471 & $1 \mathrm{ml}$ Dfs $1+1 \mathrm{ml}$ methanol \\
\hline DS 3 & 0.235 & $1 \mathrm{ml}$ Dfs $2+1 \mathrm{ml}$ methanol. \\
\hline DS 4 & 0.117 & $1 \mathrm{ml}$ Dfs $3+1 \mathrm{ml}$ methanol \\
\hline DS 5 & 0.058 & $1 \mathrm{ml}$ Dfs $4+1 \mathrm{ml}$ methanol \\
\hline
\end{tabular}

Dfs: dilute fruit solution; Dls: dilute leaves solution

\subsubsection{DPPH test protocol}

After the preparation of the dilutions of the extracts in methanol, we took $1 \mathrm{ml}$ of each extract which we put in a tank and added $1 \mathrm{ml}$ of the DPPH solution. The reaction mixture is stirred before being placed for 60 minutes in the dark and at room temperature in the laboratory. The absorbance of the reaction medium was measured at 515 nanometer (nm) using a spectrophotometer against a negative control (containing methanol instead of the extract). The percentage inhibition (I \%) of the DPPH radical by our extract is calculated as follows:

$$
\mathrm{I} \%=[(\mathrm{A} 1-\mathrm{A} 2) / \mathrm{A} 1] \times 100
$$

A 1: Negative control "Absorbance in the absence of the extract (inhibitor).

A 2: Absorbance in the presence of the extract.

\section{Results and discussion}

\subsection{Results of HPLC}

The chromatographic profiles of the methanolic extracts of leaves and fruits of Crataegus monogyna Jacq analyzed by HPLC are compared with those of the standards.

The methanolic extracts of leaves and fruits of Crataegus monogyna, appear to contain chlorogenic acid, rutin, isoquercetin, hesperidin and catechin (Figure 1).

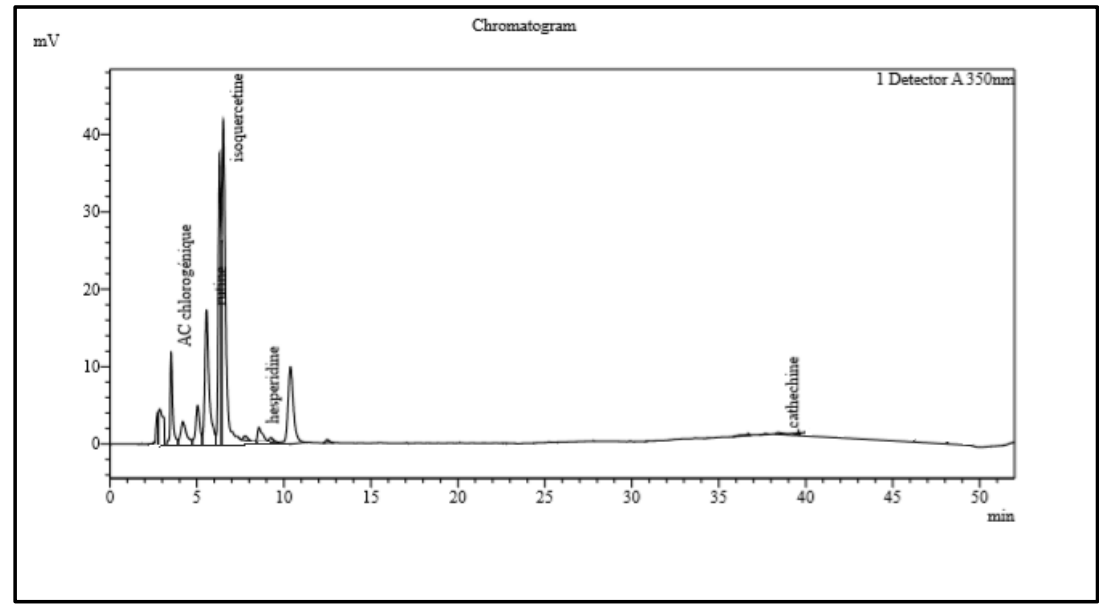

Figure 2 Chromatogram of the methanolic extract of Crataegus monogyna Jacq leaves 
The methanolic fruit extract appears to contain additional caffeic acid and quercetin (Figure 3).

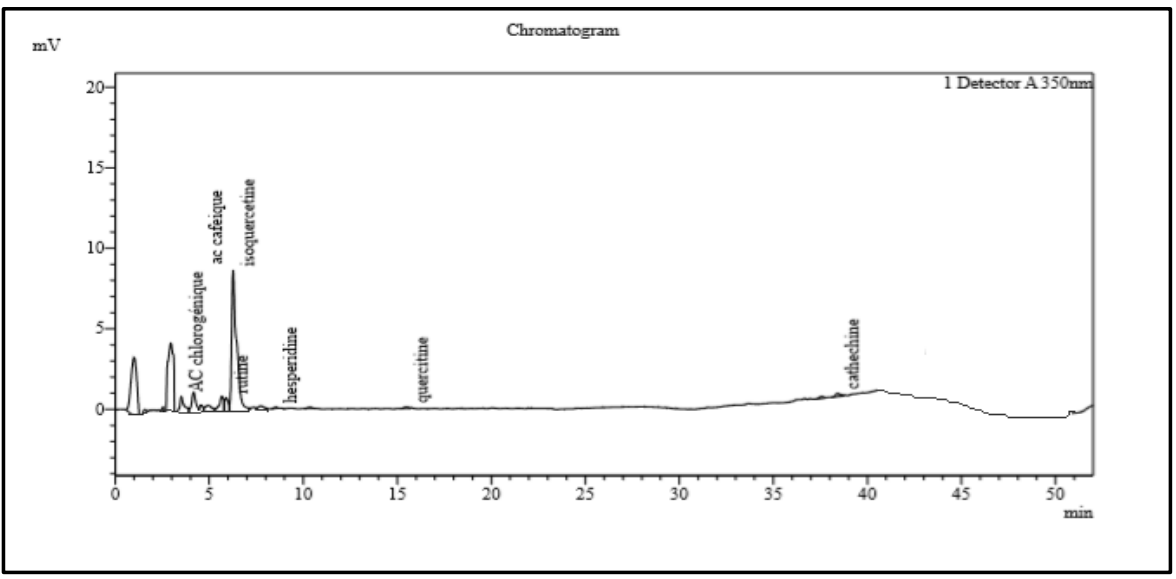

Figure 2 Chromatogram of the methanolic extract of Crataegus monogyna Jacq fruits

"Prinz [5] obtained similar results". "Sagaradze [6] also obtained the same results; it confirms the presence of rutin, quercetin and isoquercetin in extracts of leaves and flowers of Crataegus monogyna Jacq".

\subsection{Results of antioxidant activity}

The results are evaluated by spectrophotometer by following the reduction of this radical which is accompanied by the deviation of the violet color at yellow color at $515 \mathrm{~nm}$ :

In the first place, by the observation of color change (the purple color of the DPPH solution turns yellow). This color change indicates that the DPPH is reduced to 2.2 Diphenyl 1 picryl hydrazine in the presence of free radical scavengers in the extracts.

In the second place, $\mathrm{CI}_{50}$ being the concentration of the test sample necessary to reduce $50 \%$ of the DPPH radical. The results being expressed relative to those obtained for ascorbic acid, which represents the reference antioxidant and the IC50s are calculated graphically by percentages of inhibition according to the different concentrations of the extracts tested.

According to the results recorded in the previous figures:

- $\mathrm{CI}_{50}$ of ascorbic acid (reference oxidant) is $2.74 \mu \mathrm{g} / \mathrm{ml}$ (Figure 3).

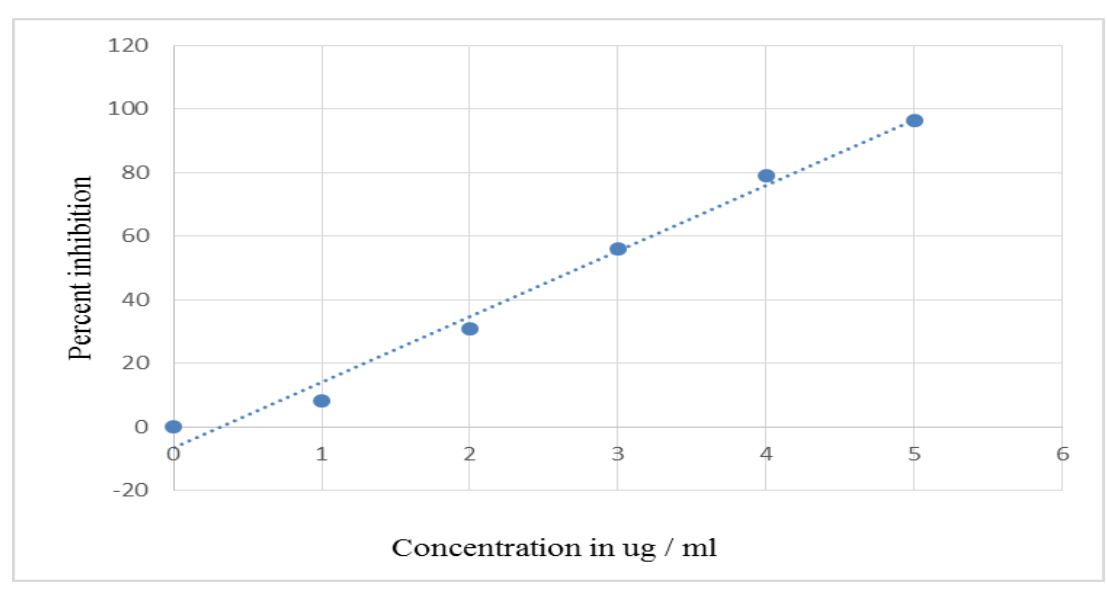

Figure 3 Curve of ascorbic acid activity

- IC 50 of the methanolic extract of Crataegus monogyna leaves is $24.59 \mu \mathrm{g} / \mathrm{ml}$ (Figure 4 ). 


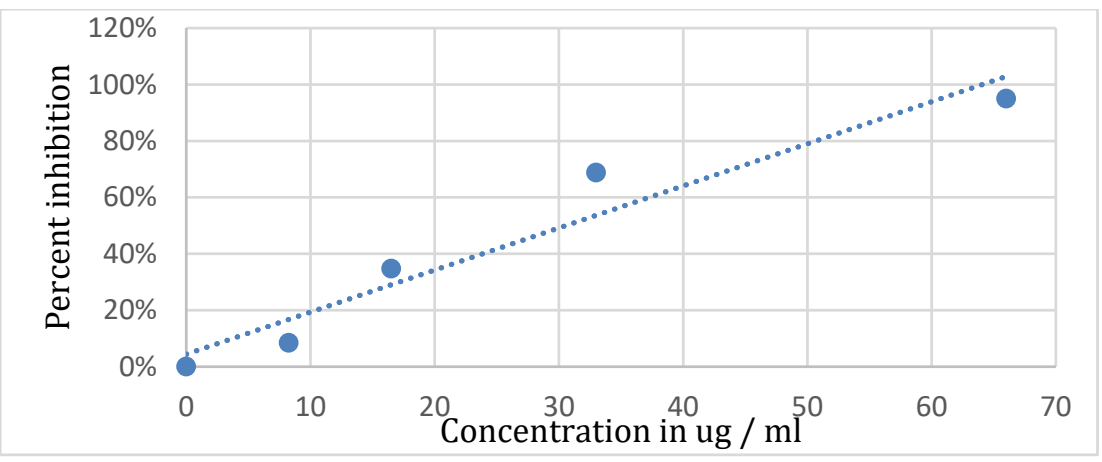

Figure 4 Curve representing the activity of the extract of Crataegus monogyna Jacq leaves

- IC 50 of the methanolic extract of Crataegus monogyna fruits is $323.87 \mu \mathrm{g} / \mathrm{ml}$ (Figure 5).

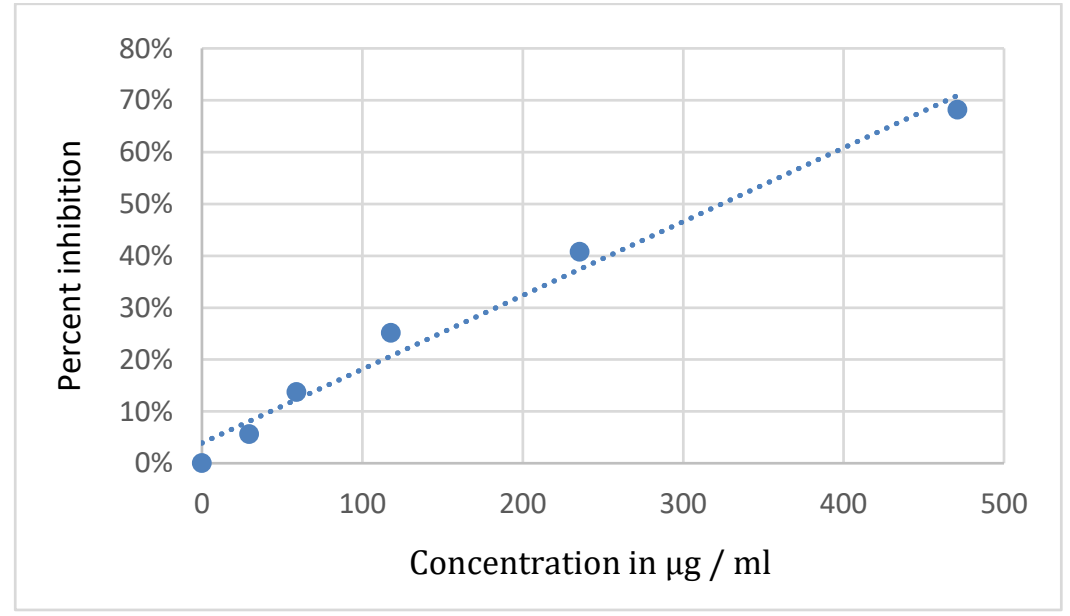

Figure 5 Curve representing the activity of the extract of Crataegus monogyna Jacq fruits

Our test results show that the methanolic extract of Crataegus monogyna Jacq leaves has greater antioxidant activity than that of the fruit extract (the CI50 of which are $24.52 \mu \mathrm{g} / \mathrm{ml}$ and $323.87 \mu \mathrm{g} / \mathrm{ml}$, respectively). This can be explained by the richness of the leaves in phenolic compounds compared to the fruits. However, the CI50 of ascorbic acid is 2.74 $\mu \mathrm{g} / \mathrm{ml}$, it is lower than that of fruits. While for the leaves, the result shows an average antioxidant activity when compared with that of the reference antioxidant. "Mraihi [7] obtained results of the antioxidant activity of the fruits of Crataegus monogyna superior to those which we obtained". However, "Barros [8] obtained lower results than we obtained for the leaf extract".

\section{Conclusion}

Analysis of methanolic extracts of Crataegus monogyna Jacq by high performance liquid chromatography revealed the presence of phenolic components in the leaves, such as chlorogenic acid, rutin and catechin. While in the methanolic extract of the fruit, we additionally note the presence of quercetin and caffeic acid. The study of the antioxidant activity of methanolic extracts of leaves and fruits of Crataegus monogyna Jacq found that the leaf extract has medium antioxidant activity, unlike the fruit extract which has low antioxidant power. It is therefore that the leaves are richer in phenolic compounds than the fruits.

\section{Compliance with ethical standards}

\section{Acknowledgments}

We thank the members of the Pharmacognosy laboratory and those of the Pharmaceutical Development and Control Laboratory of the Faculty of Medicine for the help they gave us in carrying out this work. 


\section{Disclosure of conflict of interest}

I declare and all co-authors that we participated in the design, execution and analysis of the document and that I approve the final version. In addition, there is no conflict of interest in connection with this document, and the material described is not in the process of being published nor is it intended for publication elsewhere.

\section{References}

[1] Barceloux DG. (2008). Medical toxicology of natural substances: Foods, fungi, medicinal herbs, plants, and venomous animals. John Wiley \& Sons

[2] Nagata T and Ebizuka Y. (2013). Medicinal and aromatic plants XII. Springer Science \& Business Media; 348.

[3] Laraba M, Serrat A and Ouassaa G. (2016). Étude in vitro de l'activité antioxydante des polyphénols isolés à partir d'une plante médicinale; 48-52

[4] Ferrari J and Hostettmann K. (2002). Contribution à la connaissance du métabolisme secondaires des Thymelaceae et investigation phytochimique de l'une d'elle: « Gnidia involucrata » Steud, ex A. Rich. University of Lausanne ; 200

[5] Prinz S, Ringl A, Huefner A, Pemp E and Kopp B. (2007). 4"'-Acetylvitexin-2 "-O-rhamnoside, Iso-orientin, Orientin, and 8-Methoxykaempferol-3-0-glucoside as Markers for the Differentiation of Crataegus monogyna and Crataegus pentagyna from Crataegus laevigata (Rosaceae). Chemistry \& biodiversity; 2920-2931.

[6] Sagaradze V, Babaeva E and Kalenikova, E. (2017). HPLC-UV method for determing flavonoids in Hawthorn flowers and leaves. Pharmaceutical Chemistry Journal; 277-280

[7] Mraihi F, Journi M, Chérif J, Sokmen M, Sokmen A, and Trabelsi A M. (2013). Phenolic contents and antioxidant potential of Crataegus fruits grown in Tunisia as determined by DPPH, FRAP, and $\beta$-carotene/linoleic acid assay. Journal of chemistry. University of Carthage; 4-5

[8] Barros L, Carvalho A and Ferreira I. (2011). Comparing the composition and bioactivity of Crataegus monogyna flowers and fruits used in folk medicine. Phytochemical analysis; 181-188 